\title{
Clinical and Radiographic Evaluation of Marginal Bone Loss and Periodontal Parameters after Various Dental Reconstruction Procedures
}

\author{
Mohammed M. A. Abdullah Al-Abdaly ${ }^{*}$, Anas Abdullah Q. Khawshal'2, \\ Ahmed Yahia Almojathel Alqisi², Hamoud Hassan Al-shari ${ }^{2}$, Nourah Falah Alshahrani², \\ Ayesha Nasser Alshahrani ${ }^{2}$
}

${ }^{1}$ Periodontics Department, College of Dentistry, King Khalid University, Abha, Saudi Arabia

${ }^{2}$ College of Dentistry, King Khalid University, Abha, Saudi Arabia

Email: *malabdaly20@gmail.com

How to cite this paper: Al-Abdaly, M.M.A.A., Khawshal, A.A.Q., Alqisi, A.Y.A., Al-shari, H.H., Alshahrani, N.F. and Alshahrani, A.N. (2018) Clinical and Radiographic Evaluation of Marginal Bone Loss and Periodontal Parameters after Various Dental Reconstruction Procedures. International Journal of Clinical Medicine, 9, 39-48.

https://doi.org/10.4236/ijcm.2018.91005

Received: December 29, 2017

Accepted: January 16, 2018

Published: January 19, 2018

Copyright $\odot 2018$ by authors and Scientific Research Publishing Inc. This work is licensed under the Creative Commons Attribution International License (CC BY 4.0).

http://creativecommons.org/licenses/by/4.0/

\section{Open Access}

\begin{abstract}
Background: Periodontal disease is a bacterial infection that causes bone resorption of bone supporting teeth and leads to change in the normal architecture of the alveolar process. There are instances where the technique sensitive nature of restorative procedures or the faulty restorative margins may inadvertently lead to conditions which could bring about periodontal disease/ destruction. Therefore, this study was designed to determine the impact of dental restorations type on marginal bone among some patients being treated for chronic periodontitis. Material and Methods: Three hundred patients from the periodontics clinics in college of dentistry, King Khalid university were participated in our study. A total of 292 patients completed the study, 152 males and 140 female. They were divided according to dental reconstructions into three groups: Group I was without dental reconstructions (control group), group II patients received amalgam class II fillings and group III received fixed bridge denture. Plaque index (PLI) gingival index (GI), clinical attachment loss (CAL) and marginal bone loss (MBL) were recorded. All data were collected and were analyzed by ANOVA test. Results: In the present study, the restored teeth revealed significantly higher mean values for PLI, GI, $\mathrm{CAL}$ and MBL than the non-restored teeth (p-value < 0.05). Conclusion: Although the limitations of the present study, the patients in group II had the highest clinical attachment loss and value of marginal bone loss which can explain the more extension of amalgam fillings into subgingival direction, leading to increased plaque accumulation and increased periodontal destruction.
\end{abstract}




\section{Keywords}

Chronic Periodontitis, Dental Reconstructions, Marginal of Bone Loss

\section{Introduction}

Periodontal disease is defined as a chronic inflammation of the supporting tissues of the teeth that is characterized by advanced loss of particular alveolar bone [1]. These alterations in the alveolar bone differ in shape, intensity, and allocation between persons and within the same person according to a diversity of sex, age, metabolism, oral hygiene, facial anatomy, general health, systematic illnesses, medications, parafunctions, iatrogenic factors and osteoporosis [2] [3] [4].

On the other hand the fixed dental prosthesis is considered the most common in replacement of partial missing teeth, when the dental implant is impossible. In the past clinical and histological studies, they found that there were fixed dental prostheses effect on the periodontal status of the crowning teeth; especially when the subgingival margins were extended, and there was increase in plaque accumulation and gingival inflammation compared to teeth without crowns [5] [6] [7]. Furthermore, there was highly significance in gingival index and periodontal pocket depth in the teeth with subgingival margins extension [8]. As we know that the objective of dental restorations was to return the teeth function, aesthetics and the integrity of the teeth surfaces to like normal features, but regrettably, there are not ideal dental materials that would provide the similar characteristics of normal dental structures [9].

The health of periodontal tissues in the gingival restorative area remained the most complicated area for dental restoration procedures due to the possibility of the accumulation of dental plaque on the tooth surfaces and various studies confirmed that the edges of restorations were suitable areas of accumulation of dental plaque and bacterial products producing gingival inflammation and even loss of teeth in some conditions. Consequently, dental restorative materials cannot destroy the periodontal tissues by themselves, but there are influences of dental restorative materials and cements on periodontal tissues in various methods [10].

Moreover, there were earlier studies displayed that there are differences in dental plaque adhering to dental material surfaces. All dental material surfaces can be without plaque formation if have access to dental care and are polished, but dental restorative materials have chemically and physically deterioration effects on oral mucosa [11]. It is thought that there are synergy effects between some substances which released from dental restorative material and bacterial plaque directly or indirectly to increase existent gingival inflammatory and immunity reactions which if continued will lead to bone loss [12]. Therefore, the aim of this study was to evaluate the impact of dental restorations type on marginal bone among some patients being treated for chronic periodontitis. 


\section{Materials and Methods}

\subsection{The Study Samples}

The present study was carried out in the department of periodontics and community dental sciences (PCS), college of dentistry, king Khalid university, Saudi Arabia for a period of 6 months from January 2016 to June 2017. A total of 292 patients (152 males) and (140 females) were evaluated for the effect of the dental restorations type of marginal bone loss among some patients being treated for chronic periodontitis. They were divided according to dental reconstructions into three groups, group I included 102 patients (52 males and 50 females) without dental reconstructions (control group), group II included 95 patients (50 males and 45 females) patients received amalgam class II fillings and group III included 95 patients ( 50 males and 45 females) received fixed bridge denture (FPDs) (Figure 1 and Figure 2).

The inclusion criteria were the patients had class II amalgam fillings and Fixed partial dentures, without systemic disease, non-smokers, and who had their class II amalgam fillings and FPDs for at least one year. Informed consents were obtained from the enrolled subjects after explaining the nature of the study that was according to the protocol of the scientific research committee, college of dentistry, king Khalid University.

\subsection{Clinical Examination}

The observation methods and clinical examination by explorer and periodontal probe were used to check, correct and fit margin, restoration surface roughness and periodontal status consequently plaque index (PLI) [13], gingival index (GI) [14] and clinical attachment loss (CAL) were evaluated by the William's periodontal probe. The position of fillings and crown margins were also evaluated. The margins were sub-gingivally if they were $1 \mathrm{~mm}$ or more below the gingival margin.

\subsection{Radiographic Examination}

Dental panoramic radiographs were used for radiographic examination as an overview of the affected structures. Measurements of the distance between cemento-enamel junction (CEJ) and bone level (BL), was done with a calliper to the nearest $0.1 \mathrm{~mm}$.

If one or more of these landmarks could not be determined or caries had destroyed the cemento-enamel junction the tooth was excluded from the study (Figure 3 and Figure 4).

All clinical parameters and radiographic findings were recorded and calibrated according to the calibration protocol of Smith et al. [15]. The collected data were statistically analyzed using the ANOVA test. The descriptive statistical analyses were done and the various in the clinical parameters between study groups and control group were evaluated. The significance differences were recorded ( $\mathrm{p}$ value $<0.05)$ 


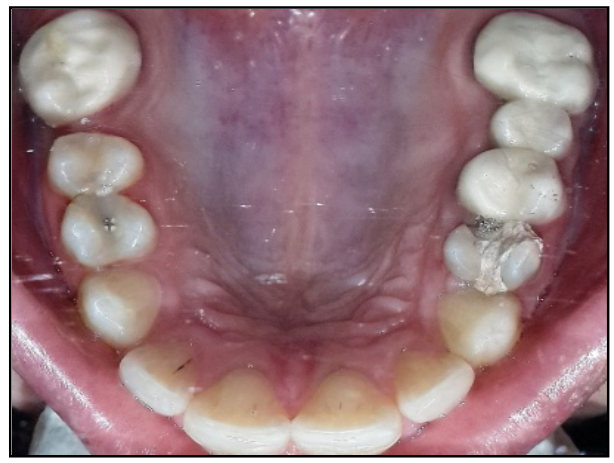

Figure 1. Clinical examination of patient with amalgam filling.

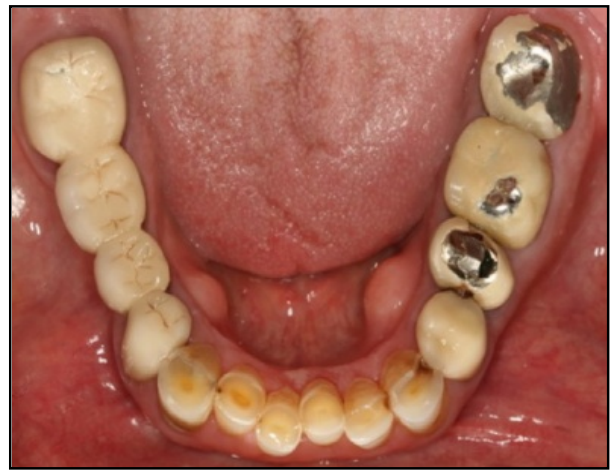

Figure 2. Clinical examination of patient with fixed partial.

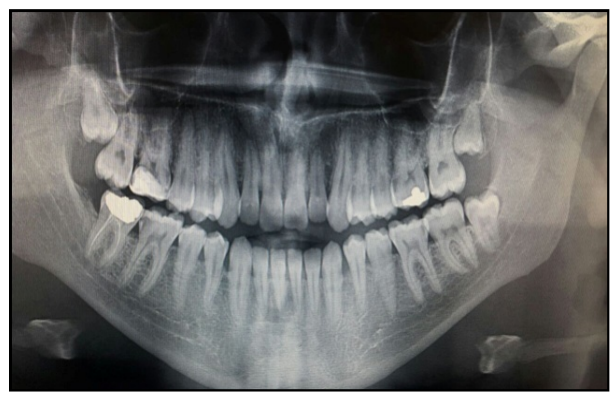

Figure 3. Radiographic of evaluation of patient with amalgam filling class.

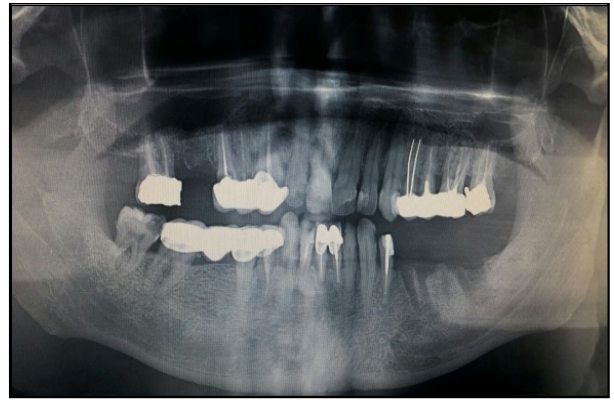

Figure 4. Radiographic evaluation of patient with fixed partial denture. 


\section{Results}

The current study was designed for the patients who were treated in the department of periodontics and community dental sciences (PCS), college of dentistry, king Khalid university, Saudi Arabia within the maintenance phase of periodontal therapy. This study included a total of 292 subjects who were treated with amalgam class II fillings and fixed partial denture since 6 months ago. The subjects included of 152 males (52.1\%) and 140 females (47.9\%).

The results are appearing in Table 1 and Table 2 and in Figure 5 and Figure 6 In Table 1 and Figure 5 the mean of age and standard deviation $( \pm S D)$ are reported. In group I the age ranged from 19 to $65 \mathrm{ys}$ by mean and \pm SD (38.1 \pm $11.8)$. In group II the age ranged from 20 to $60 y$ s by mean and \pm SD $(38.8 \pm 12.6)$. In group III the age ranged from 22 to $65 \mathrm{ys}$ by mean and $\pm \mathrm{SD}(37.1 \pm 10.6)$. Table 1 and Figure 1 show that is, no significant difference between groups regarding age where $\mathrm{F}=0.464$ and $\mathrm{P}$-value $=0.629$ (more than 0.05 ).

Table 2 and Figure 6 reports the periodontal and radiographic findings where group III showed an increase in PLI, GI, CAL and MBL compared to GI and GII. The mean and \pm SD of PLI in group II is more than group I and group III. This is a statistically significant difference $\left(P=0.005^{\star}\right)$. The main and \pm SD of PLI group II is $(1.6 \pm 0.6)$.

The mean and \pm SD of PLI in group III is higher than group I and less than PLI in group II and there were significance differences in PLI in the comparison between the groups in the present study $(\mathrm{p}<0.05)$ also the mean and \pm SD of GI in group III is higher than group I and less than GI in group II and there were significance differences in GI in the comparison between the groups in the present study $(\mathrm{p}<0.05)$.

The mean and $\pm \mathrm{SD}$ of CAL in group II is more than CAL in group I and nearly equal group III. This difference is statistically significant between group I and group II but no significant between other groups $(\mathrm{p}>0.05)$. The maximum of CAL in group II equals $(2.9 \pm 1.5)$ while it is $(2.6 \pm 1.8)$ in group III. The mean and \pm SD of CAL in group III is greater than group I. The mean \pm SD of CAL in group II is more than group I and group III.

Like other three indices studied here, the mean and \pm SD of MBL is higher in group II than group I and group III. This difference is statistically significant. (P $\left.\leq 0.001^{\star}\right)$ The mean and \pm SD of MBL is maximum in group II, it is nearly equal to mean and \pm SD MBL in group III. Maximum and the minimum is $2.6 \pm 0.2$ in

Table 1 . The mean and \pm SD of the age.

\begin{tabular}{|c|c|c|c|c|c|c|c|c|}
\hline \multirow[b]{3}{*}{ Group I } & \multicolumn{6}{|c|}{ Age } & \multicolumn{2}{|c|}{ ANOVA } \\
\hline & \multicolumn{3}{|c|}{ Range } & \multirow{2}{*}{$\begin{array}{l}\text { Mean } \\
38.093\end{array}$} & \multirow{2}{*}{$\begin{array}{l} \pm \\
\pm\end{array}$} & \multirow{2}{*}{$\begin{array}{c}\text { SD } \\
11.769\end{array}$} & \multirow[t]{2}{*}{$\mathrm{F}$} & \multirow[t]{2}{*}{$P$-value } \\
\hline & 19 & - & 65 & & & & & \\
\hline Group II & 20 & - & 60 & 38.746 & \pm & 12.562 & 0.464 & 0.629 \\
\hline Group III & 22 & - & 65 & 37.078 & \pm & 10.617 & & \\
\hline
\end{tabular}


Table 2. Periodontal findings.

\begin{tabular}{|c|c|c|c|c|c|c|c|c|}
\hline \multirow{2}{*}{ Groups } & \multicolumn{6}{|c|}{ Clinical results } & \multicolumn{2}{|c|}{ Bone Lose } \\
\hline & PLI & $P$ value & GI & $P$ value & CAL & $P$ value & Bone lose & $P$ value \\
\hline I & $1.3 \pm 0.6$ & & $1.3 \pm 0.4$ & & $1.8 \pm 1.6$ & & $1.1 \pm 0.9$ & \\
\hline II & $1.6 \pm 0.6$ & $0.005^{*}$ & $1.5 \pm 0.5$ & $0.011^{\star}$ & $2.9 \pm 1.5$ & 0.863 & $2.6 \pm 0.2$ & $<0.001^{*}$ \\
\hline III & $1.4 \pm 0.5$ & & $1.4 \pm 0.4$ & & $2.6 \pm 1.8$ & & $2.1 \pm 0.3$ & \\
\hline
\end{tabular}

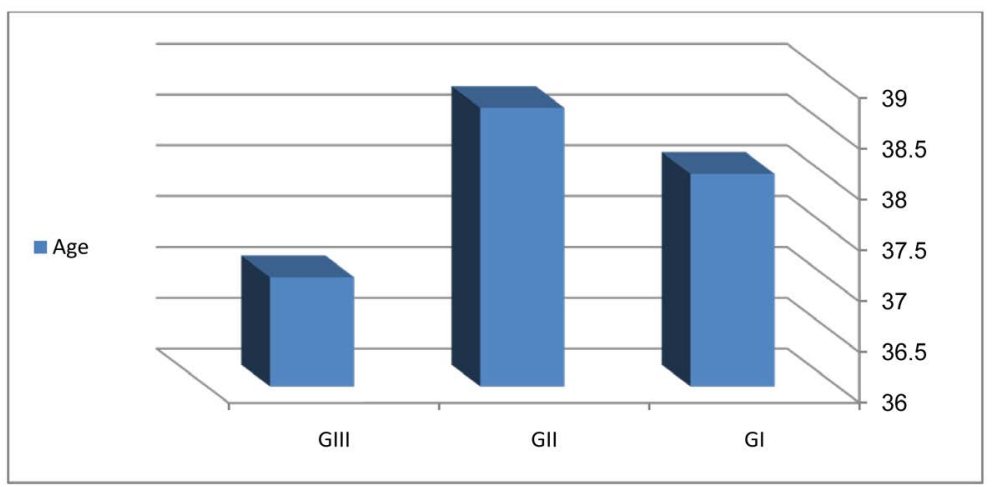

Figure 5. Age of patients groups.

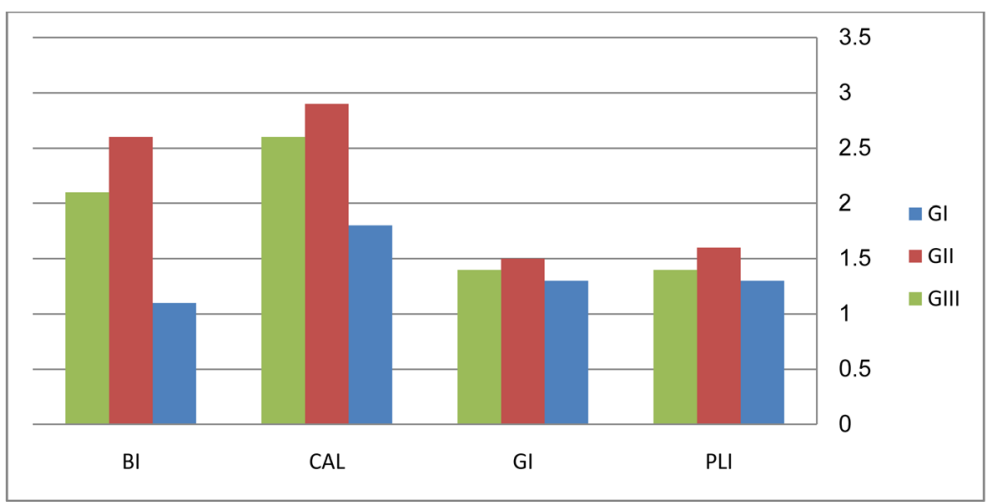

Figure 6. Periodontal findings.

group II and $1.1 \pm 0.9$ in the control group. The mean and \pm SD of MBL in group III is a higher than in the control group.

In the present study, the restored teeth revealed significantly higher mean values for PLI, GI, CAL and MBL than the non-restored teeth (p-value < 0.05). In all participants, the restored teeth had sub-gingival margins of crowns and amalgam class II fillings and presented with significantly higher mean values of PLI, GI, CAL and MBL in comparison to control group ( $\mathrm{p}$-value $<0.05$ ).

\section{Discussion}

Dental restorations have sufficient effect to change the oral environment. The disruptions between normal and pathogenic bacteria in the oral cavity causes increased plaque formations and exacerbation of periodontal diseases [16]. 
Consequently, there are exceedingly relationship between periodontal health and dental restorations: The dental restorations are fundamental for periodontal preservations and periodontal health is necessary for correction and stimulation of dental restorations function [17].

There were different studies displayed that over-contoured crowns, ill design, and sub-gingival positioning of dental restorations can participate as local risk factors of periodontal diseases and many of these studies have appeared that the sub-gingival margins clash on the periodontal tissues with the rising plaque formation are considered as causes in the progression of periodontal destruction [18] [19] [20] [21]. Therefore, our study was designed to evaluate the effect of dental restorations type on marginal bone loss.

In a study that was carried out by Luthardt and Mandy Stobel in 2000, there were significantly increased in plaque accumulation around temporary bridges and crowns [22] which agrees with the results in our study, but a 10-day experimental gingivitis and temporary study that is done by Van Dijken, Claesson and Konradsson in 2007 displayed that there was no significance differences in PLI and GI between the teeth without dental restorations and the teeth with composite and ceramic dental restorations [23]. On the other hand, in an experimental 7-day gingivitis study on different materials that made by Van Dijkan and Sjostrom in 1998, there were no significance differences in PLI and GI between the different filling materials [24].

The present study results showed an increase in the plaque and gingival indices in majority of the study subjects. In addition, the mean and $\pm \mathrm{SD}$ of plaque and gingival indices in restoring teeth scored significantly higher than the mean and \pm SD scores of plaque and gingival indices of non-restored teeth. These findings are in agreement with different other studies deciding increased plaque formation and gingival inflammation on teeth with dental restorations and there is a public agreement of the closely related between the dental plaque and presence of gingivitis [25] [26]. In another study on FPDs (Fixed Partial denture) and crowns that was carried out by Kent Kent et al., in 2002, there was increased in progressive of gingival inflammation neighboring to dental restorations particularly when the margins extend subgingivally, rough surface and poor adaptation, these findings agree with the results of our study. Moreover the periodontal pocket depth, loss of attachment and the radiographic evidence of bone loss were utilized as adjective information to supply data of the periodontal tissue changes in teeth with restorations and not as manifestations of disease activity [25].

The current study showed that there were increased in CAL and MBL in all patients of the study groups compared to the patients of control group where the mean and $\pm \mathrm{SD}$ values of CAL and MBL were more in restorated teeth than non-restored teeth. These findings are considered as a result of increased accumulation of dental plaque and progression of gingival inflammation. The same findings were observed in the past by Silness and Bader et al. who detected that 
increased the amount of dental plaque, gingival inflammation, attachment loss and bone loss on teeth with dental restorations more than teeth without dental restorations [7] [27].

The limitations of the current study and the previous studies stay the shortage in radiographic diagnosis to assess the relation between dental restorations and the extension of bone loss moreover the difficulty to determine the criteria of importance a good dental reconstruction for the long-term impact on the patients oral hygiene and periodontal status.

\section{Conclusion}

Despite the difficulties in the present study, we reached that the restored teeth with amalgam fillings (class II) have more plaque formation, gingival inflammation, clinical attachment loss and marginal bone loss than the restored teeth with crowns and the non-restored teeth (control group).

\section{Acknowledgements}

The authors would like to thank the staff in outpatient clinics, College of dentistry, King Khalid University for their great role in the success of this scientific work.

\section{References}

[1] Papapanou, P.N. and Wennström, J. (1991) The Angular Bony Defect as Indicator of Further Alveolar Bone Loss. Journal of Clinical Periodontology, 18, 317-322. https://doi.org/10.1111/j.1600-051X.1991.tb00435.x

[2] Goldman, H.M. and Cohen, W. (1968) Periodontal Therapy. The CV Mosby Company, St. Louis, 80-82.

[3] Kreisler, M., Behneke, N., Behneke, A. and d'Hoedt, B. (2003) Residual Ridge Resorption in the Edentulous Maxila in Patients with Implant-Supported Mandibular Overdentures: An 8-Years Retrospective Study. The International Journal of Prosthodontics, 16, 265-300.

[4] Carlsson, G.E. (2004) Responses of Jawbone to Pressure. Gerodontology, 21, 65-70. https://doi.org/10.1111/j.1741-2358.2004.00005.x

[5] Hebel, K., Gajjar, R. and Hofstede, T. (2000) Single-Tooth Replacement: Bridge vs. Implant-Supported Restoration. Journal of the Canadian Dental Association, 66, 435-438.

[6] Gardner, F.M. (1981) Margins of Complete Crowns-Literature Review. JProsth Dent, 48, 396-400.

[7] Silness, J. (1970) Periodontal Conditions in Patients with Dental Bridges. III. The Relationship between the Location of the Crown Margin and the Periodontal Condition. Journal of Periodontal Research, 2, 225-229. https://doi.org/10.1111/j.1600-0765.1970.tb01839.x

[8] Kois, C. (1996) The Restorative-Periodontal Interface: Biological Parameters. Periodontol 2000, 11, 29-31. https://doi.org/10.1111/j.1600-0757.1996.tb00180.x

[9] Albandar, J.M., Buischi, Y.A. and Axelsson, P. (1995) Caries Lesions and Dental Restorations as Predisposing Factors in the Progression of Periodontal Diseases in 
Adolescents. A 3 Year Longitudinal Study. Journal of Periodontology, 66, 249-254. https://doi.org/10.1902/jop.1995.66.4.249

[10] App, G. (1961) Effect of Silicate, Amalgam and Cast Gold on the Gingiva. Journal of Prosthetic Dentistry, 11, 522. https://doi.org/10.1016/0022-3913(61)90235-9

[11] Kawakara, H., Yamagani, A. and Nakamura Jr., M. (1968) Biologic Testing of Dental Materials by Means of Tissue Culture. International Dental Journal, 18, 443.

[12] Waerhaug, J. and Zander, H. (1957) Reaction of Gingival Tissue to Self-Curing Acrylic Restorations. The Journal of the American Dental Association, 54, 760. https://doi.org/10.14219/jada.archive.1957.0120

[13] Silness, J. and Loe, H. (1964) Periodontal Disease in Pregnancy II. Correlation between Oral Hygiene and Periodontal Condition. Acta Odontologica Scandinavica, 22, 122-135. https://doi.org/10.3109/00016356408993968

[14] Löe, H. and Silness, J. (1963) Periodontal Disease in Pregnancy I. Prevalence and Severity. Acta Odontologica Scandinavica, 21, 533-551. https://doi.org/10.3109/00016356309011240

[15] Smith, L., Suomi, J., Greene, J. and Barbano, J. (1970) A Study of Intra-Examiner Variation in Scoring Oral Hygiene Status, Gingival Inflammation and Epithelial Attachment Level. Journal of Periodontology, 41, 671-674. https://doi.org/10.1902/jop.1970.41.12.671

[16] Nunn, M.E. (2003) Understanding the Etiology of Periodontitis: An Overview of Periodontal Risk Factors. Periodontology 2000, 32, 11-23. https://doi.org/10.1046/j.0906-6713.2002.03202.x

[17] Kells, B.E. and Linden, G.J. (1992) Overhanging Amalgam Restorations in Young Adults Attending a Periodontal Department. Journal of Dentistry, 20, 85-89. https://doi.org/10.1016/0300-5712(92)90110-X

[18] Ehrlich, J. and Hochman, N. (1980) Alterations on Crown Contour-Effect on Gingival Health in Man. Journal of Prosthetic Dentistry, 44, 523-525. https://doi.org/10.1016/0022-3913(80)90071-2

[19] Felton, D., Kanoy, B. and Bayne, S. (1991) Effect of In Vivo Crown Margin Discrepancies on Periodontal Health. Journal of Prosthetic Dentistry, 65, 357-364. https://doi.org/10.1016/0022-3913(91)90225-L

[20] Valderhaug, J., Ellingsen, J. and Jokstad, A. (1993) Oral Hygiene, Periodontal Conditions and Carious Lesions in Patients Treated with Dental Bridges. A 15-Year Clinical and Radiographic Follow-Up Study. Journal of Clinical Periodontology, 20, 482-489. https://doi.org/10.1111/j.1600-051X.1993.tb00395.x

[21] Gullo, C.A. and Powell, R.N. (1979) The Effect of Placement of Cervical Margins of Class II Amalgam Restorations on Plaque Accumulation and Gingival Health. Journal of Oral Rehabilitation, 6, 317-322.

[22] Luthardt, R.G., Stößel, M., Hinz, M. and Vollandt, R. (2000) Clinical Performance and Periodontal Outcome of Temporary Crowns and Fixed Partial Dentures: A Randomized Clinical Trial. The Journal of Prosthetic Dentistry, 83, 32-39. https://doi.org/10.1016/S0022-3913(00)70086-2

[23] Konradsson, K., Claesson, R. and van Dijken, J.W. (2007) Dental Biofilm, Gingivitis and Interleukin-1 Adjacent to Approximal Sites of a Bonded Ceramic. Journal of Clinical Periodontology, 34, 1062-1067. https://doi.org/10.1111/j.1600-051X.2007.01146.x

[24] Van Dijken, J.W. and Sjöström, S. (1998) Development of Gingivitis around Aged Restorations of Resin-Modified Glass Ionomer Cement, Polyacid-Modified Resin 
Composite (Compomer) and Resin Composite. Clinical Oral Investigations, 2, 180-183. https://doi.org/10.1007/s007840050067

[25] Knoernschild, K.L. and Campbell, S.D. (2000) Periodontal Tissue Responses after Insertion of Artificial Crowns and Fixed Partial Dentures. Journal of Prosthetic Dentistry, 84, 492-498. https://doi.org/10.1067/mpr.2000.110262

[26] Drisko, C. (2001) Nonsurgical Periodontal Therapy. Periodontology 2000, 25, 77-88. https://doi.org/10.1034/j.1600-0757.2001.22250106.x

[27] Bader, J., Rozier, R., McFall, W. and Ramsey, D. (1991) Effect of Crown Margins on Periodontal Conditions in Regularly Attending Patients. Journal of Prosthetic Dentistry, 65, 75-79. https://doi.org/10.1016/0022-3913(91)90053-Y 